\title{
Apoio familiar na compreensão do diagnóstico e empoderamento de homens com diabetes mellitus
}

\author{
Geysa Maria Nogueira Farias (iD \\ Universidade de Fortaleza - Fortaleza (CE) - Brasil
}

Laurineide de Fátima Diniz Cavalcante (iD

Universidade de Fortaleza - Fortaleza (CE) - Brasil

José Reginaldo Pinto (iD

Universidade de Fortaleza - Fortaleza (CE) - Brasil

Marilia Machado Matos

Universidade de Fortaleza - Fortaleza (CE) - Brasil

Lorena Falcão Lima iD

Universidade de Fortaleza - Fortaleza (CE) - Brasil

Maria Edilândia Alencar Caldas iD

Universidade de Fortaleza - Fortaleza (CE) - Brasil

Raissa Vidigal Carneiro iD

Universidade de Fortaleza - Fortaleza (CE) - Brasil

Danielle Teixeira Queiroz (iD

Universidade de Fortaleza - Fortaleza (CE) - Brasil

\section{RESUMO}

Objetivo: Identificar como ocorre o empoderamento dos homens com diabetes mellitus para autogestão de sua condição crônica, além de compreender suas motivações e barreiras para realizar o autocuidado. Métodos: Estudo descritivo com referencial qualitativo realizado em 2017, tendo como cenário da pesquisa uma unidade de referência secundária para o atendimento interprofissional da população masculina com diabetes mellitus, situada em Fortaleza, Ceará, Brasil, através de entrevista aberta. Resultados: A análise dos dados empíricos ocorreu por categorização temática e possibilitou a construção de dois temas: motivações para busca de assistência profissional e apoio familiar como suporte para o empoderamento do autocuidado. Evidenciou-se a procura por ajuda profissional ao inicio dos sinais e sintomas da doença e apoio familiar como suporte e envolvimento para o controle metabólico e bem-estar, ajudando-os no tratamento. Identificou-se dificuldade e restrição em expressar sentimentos em relação a doença, para esconder sua vulnerabilidade. Conclusão: Pode-se inferir que os entrevistados procuram ajuda profissional, mas resistem participar de grupo de autoajuda e destacou-se o envolvimento e o apoio da família como fundamentais para o progresso do tratamento e empoderamento do autocuidado.

Descritores: Diabetes Mellitus; Saúde do Homem; Vulnerabilidade Individual; Empoderamento.

\section{INTRODUÇÃO}

Estima-se que em 2045 haverá 42,3 milhões de pessoas com diabetes mellitus (DM) na América Central e do Sul. No Brasil foram diagnosticados 12, 5 milhões de casos em $2017^{(1)}$. Por seu carater crônico, a diabetes destaca-se pela alta morbimortalidade com a instalação de complicações agudas e crônicas, além dos significativos custos no controle e tratamento dessa condição multifatorial ${ }^{(2-4)}$.

Após o diagnóstico existe um processo de adaptação como um todo, fisicamente e principalmente psicologicamente, pois a nova realidade pode ocasionar uma desorganização na dinâmica familiar, e tudo depende de como se encara

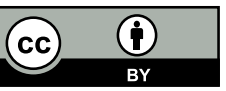


o significado da doença e do tratamento. A nova realidade ao qual a família precisará conviver possibilitará muitas oportunidades de aprendizagem sobre a doença. Após passar a confirmação do diagnóstico, indivíduos e familiares vão buscar métodos para enfrentá-la, buscando apoio psicossocial, espiritual para uma nova caminhada que irão enfrentar e a complexidade em que o tratamento impõe, como também mudança no seu estilo de vida(5).

Ainda na perspectiva do autor acima, o suporte é um dos meios para lidar com vários fatores adversos que a doença acarreta. Esse, pode vir de diversas maneiras, uma delas é o apoio familiar. Além disso, eles também necessitam contar com o apoio psicológico para se fortalecerem emocionalmente, e seguir medidas terapêuticas de autocuidado, reconhecendo a importância do acompanhamento centrado na mudança de estilo de vida. Vale ressaltar a importância para os indivíduos, familiares e até mesmo os cuidadores, da educação em saúde para um convívio harmônico com a doença $a^{(5-8)}$.

A educação é uma estratégia que favorece o empoderamento do autocuidado dos indivíduos com DM e destaca-se por ser conceituado como uma ferramenta capaz de ensinar os indivíduos cuidarem da sua condição cônica, estabelecendo a autogestão e consequentemente a autonomia na tomada de decisões e autocuidado. Dessa forma, as pessoas com essa condição torna-se um colaborador, com participação ativa e efetiva no cuidado à sua saúde, o que favorece a melhora dos seus indicadores clínicos e o aumento significativo de sua sobrevidaa(6,8-10).

Nesse contexto, vale salientar a importância do trabalho multiprofissional nos diferentes espaços e serviços de saúde, bem como, o envolvimento da família nesse processo educativo e no planejamento das ações para adesão do individuo ao seu controle metabólico. Desse modo, a dinâmica familiar influencia significativamente na saúde de cada um de seus membros causando influências recíprocas, por ser considerada o primeiro grupo de relações afetivas geradas pelos laços biológicos, legais ou reais ${ }^{(11,12)}$.

Compreendendo que a família necessita ser envolvida no monitoramento da adesão e no empoderamento do autocuidado por parte do individuo com diabetes, o suporte familiar é caracterizado pelo apoio ofertado e mediado por regras, entre atores familiares diversos, sem expressão de autoritarismo ou de controle predominante, como forma de ajuda para o controle metabólico e prevenção das complicações. Esse estudo é relevante porque pode favorecer o conhecimento das redes de suporte que os homens com DM usam para ajudá-los no enfrentamento dos problemas e complicações decorrentes da doença. Assim, a partir desse conhecimento será possível realizar estratégias que promovam melhoria na qualidade de vida das pessoas com DM, uma vez que muitas vezes as pessoas quando descobrem a doença ficam depressivas, angustiadas e negam a doença, o que dificulta a adesão ao tratamento.

Dessa forma, essa pesquisa tem como objetivo identificar como ocorre o empoderamento dos homens com diabetes mellitus para autogestão de sua condição crônica, além de compreender suas motivações e barreiras para realizar o autocuidado.

\section{MÉTODOS}

Pesquisa descritiva e qualitativa, realizada em um serviço de referência secundária em Fortaleza, Ceará, Brasil, no primeiro semestre de 2017, nos ambulatórios especializados em cardiologia, nefrologia, endocrinologia, neurologia e geriatria. Esse local foi escolhido como campo de coleta de dados em virtude de ser uma unidade de referência em atenção secundária para pessoas com complicações relacionadas ao DM.

Participaram do estudo 14 homens com diagnóstico de DM, selecionados de acordo com os seguintes critérios: estar em acompanhamento no serviço a pelo menos um ano e não possuir nenhuma deficiência mental que impossibilitasse-o a responder a entrevista.

A entrevista ocorreu antes das consultas especializadas, individualmente com cada usuário numa sala reservada, utilizando apoio de um gravador digital. Foi usado roteiro semiestruturado, contendo dois blocos: um com dados sociodemográficos e quatro perguntas abertas: 1 . Durante a descoberta da doença você procurou ajuda? 2. Comente como foi esse momento? 3. Como ficou seu relacionamento familiar após a descoberta da doença? 4. Comente como você faz para falar sobre sua doença, frequenta algum grupo de autoajuda dentro do seu bairro ou na sua comunidade?

Após as entrevistas, os depoimentos foram transcritos, organizados detalhadamente, agrupados, extraídos os núcleos de significados e, em seguida, classificados em temáticas ${ }^{(13)}$ : motivações para buscar assistência profissional, governança familiar como suporte para o empoderamento do autocuidado.

Esse estudo é parte de um projeto ampliado intitulado "Atenção à saúde das pessoas com Diabetes Melitus na Cidade de Fortaleza-CE: Abordagem integrada de aspectos epidemiológicos, clínicos e o impacto do uso de tecnologia para redução da morbimortalidade", com Parecer de aprovação ética nº 1.790.525. 


\section{RESULTADOS E DISCUSSÃO}

O material empírico permitiu a construção das seguintes temáticas: motivações para buscar assistência profissional e governança familiar como suporte para o empoderamento do autocuidado.

\section{Motivações para buscar assistência profissional}

A primeira temática foi identificada ao ser questionado como foi o momento da descoberta da doença e permitiu mostrar que grande parte dos entrevistados procurou ajuda profissional, por perceber que algo estava errado, diante da presença de tantos sintomas indesejados. Pode-se perceber pelos seguintes relatos:

"Sim, procurei um médico e ele passou uns exames depois dos resultados viu que estava com essa doença e passou o tratamento". (H1)

"Sim, fiz exames e o médico disse que eu tinha que parar de comer açúcar, tomar remédio na hora certa e fazer caminhada" (H2)

"Sim, depois de muito mal estar fui ao posto mais próximo da minha casa e a doutora fez um teste do furo no meu dedo e descobri essa doença" (H5)

"Sim, muita tontura que sentia e a visão turva depois disso procurei o médico mais próximo da minha casa" (H11)

"Sim, não estava me sentindo bem com fraqueza e tonturas e depois de desmaios, procurei o doutor." (H12)

Nos discursos foi notório os homens procuraram assistência ao se depararem com sintomas fora do normal e percebe-se em outro estudo, situação semelhante, revelando que o momento do diagnóstico é muito significativo, uma vez que traz mudanças no estilo de vida como: prática de exercício físico e alimentação diferenciada para o alcance do sucesso no tratamento ${ }^{(14)}$. Além disso, o indivíduo com alguma doença crônica desenvolve mecanismos para conviver em harmonia com sua doença ${ }^{(15)}$.

\section{Governança familiar como suporte para o empoderamento do autocuidado}

A temática seguinte mostrou que grande parte dos familiares se envolveram com o bem-estar do paciente após o diagnóstico, melhorando assim a qualidade de vida, e ajudando na adesão ao tratamento. Percebe-se nos seguintes relatos:

"Minha companheira me ajudou muito sempre fazendo tudo para eu comer direito." (H2)

"Bem, minha esposa é sempre muito atenciosa com a hora dos remédios e na alimentação também." (H4)

"Tranquilo, minha esposa sempre me motiva muito, na alimentação e faz caminhada comigo." (H6)

"Bem, consigo me regrar na alimentação e procuro tomar os remédios na hora."(H8)

"Tranquilo, minha esposa me apoia e meus filhos também, e ela faz a comida do jeito que o médico pede." (H12)

A família é uma entidade de extrema importância na adesão ao tratamento, principalmente aquele de longa duração. É significativo entender e lidar com o comportamento de todos que convivem no mesmo lar, uma vez que, a saúde ou doença de cada indivíduo influencia no funcionamento e na dinâmica da família. Mostra-se que a família carrega um peso, uma importância essencial, no sentido de estimular, incentivar a pessoa com DM para seguir corretamente o tratamento proposto, e que possa aderir a ele e ter uma vida tranquila e com qualidade ${ }^{(5)}$.

A família é a entidade de cuidado mais importante ao individuo com uma condição crônica. Esse é influenciado pelo aspectos culturais, como as crenças, valores e significados compartilhados, além da situação socioeconômicas e educacionais em que vivem. Nessa perspectiva, os cuidados em saúde tendem a ser interpretados a partir do seu contexto cultural histórico, o que desencadeia mudanças positivas ou não nos hábitos de vida de seus membros, se traduzindo no empoderamento do autocuidado ${ }^{(16-18)}$.

Os discursos masculinos possibilitaram perceber certa restrição na busca por ajuda. Ficando mais evidente as dificuldades de expressão sentimental que o sexo masculino mostra ao revelar que não precisam de apoio e muito menos de engajamento em grupo de autoajuda dentro do seu bairro, ou na comunidade, o que pode ser considerada uma demonstração de fraqueza. Dessa forma, alguns acabam afirmando que não precisam de ajuda profissional, se sentindo invulneráveis por sempre acharem que está tudo bem. Nota-se nos seguintes relatos:

"Não frequento nenhum grupo até porque essa doença não é contagiosa e ainda tem como controlar. Falo normal." (H2) 
"Não tem muito o que ficar falando e nem para quem falar é uma doença que vivemos normal." (H8)

"Não tenho o que falar não. Falo com minha filha, é uma coisa normal e também não frequento nada não." (H9)

"Não comento com ninguém a não ser as pessoas da minha família e os médicos e agentes de saúde quando vão à minha casa saber como estou." (H11)

Os homens tendem a ter mais dificuldades sobre procurar assistência profissional, adoecer e falar de saúde em si. Na maioria das vezes escondem seus sintomas para não demonstrar suas necessidades e com isso restringem o apoio profissional. Quando se trata de doença, então eles evitam até o conhecimento da mesma. Normalmente os homens não fazem parte das populações que mais frequentam os serviços de atenção básica à saúde. $O$ uso dos serviços de saúde pelos homens é diferente. Geralmente só buscam a assistência em casos extremos de emergência e urgência, dificilmente procuram por um atendimento em geral, como uma consulta agendada ou investigar algo, algum sintoma ${ }^{(19)}$.

Assim, eles só chegam aos serviços de saúde em situações graves ou quando se veem incapazes de trabalhar, logo, não buscam os serviços para fins preventivos ${ }^{(20)}$. Contudo, a realidade vivenciada mostra que a população masculina se considera invulnerável, mas isso deve servir de desafio para que o enfermeiro busque caminhos para oportunizar o acesso dos homens aos serviços de saúde para prevenção de agravos e complicações, bem como para estimular o autocuidado.

\section{CONCLUSÃO}

Em relação aos resultados percebe-se que grande parte dos homens entrevistados procurou ajuda profissional durante o surgimento dos sinais e sintomas. Observou-se que a família é sua principal parceira no suporte metabólico como também no empoderamento do autocuidado, uma vez que ela o ajuda a enfrentar o cotidiano do tratamento com menos ansiedade e isso lhes dão motivação para a busca do serviço de saúde, mesmo ainda com uma visão masculina reducionista e machista que resiste em se enganjarem nos grupo de apoio.

Dessa forma, vale salientar que mesmo conhecendo a doença, a relação do profissional com o paciente precisa de maior aproximação, para que seja formado um vínculo e esse se traduza em estímulos na busca de ajuda e no empoderamento.

\section{REFERÊNCIAS}

1. International Diabetes Federation (IDF). Diabetes Atlas. Eighth edition [Internet]. IDF; 2017 [acesso em 2019 Mai 26]. Disponível em: http://www.diabetesatlas.org/.

2. Li L, Ji L, Guo X, Ji Q, Gu W, Zhi X, et al. Prevalence of microvascular diseases among tertiary care Chinese with early versus late onset of type 2 diabetes. J Dia betes Complications. 2015;29(1):32-7.

3. American Diabetes Association (ADA). Standards of medical care in diabetes - 2017. Diabetes Care. 2017;40(sup 1):6-10.

4. Nogueira CD, Santos JC, Macedo MML, Silva SDA, Afonso RI, Carvalho TH. Efeito de um programa educacional em empoderamento do autocuidado para cumprimento de metas em diabetes. Cienc Enferm. 2018;24:3.

5. Santos MA, Alves RCP, Oliveira VA, Ribas CRP, Teixeira CRS, Zanetti ML. Representações sociais de pessoas com diabetes acerca do apoio familiar percebido em relação ao tratamento. Rev Esc Enferm USP. 2011;45(3):651-8.

6. Silva tp, Lopes GKW, Caprara A, Amorim GAM, Oliveira GC, Moreira TMM. Acesso, prática educativa e empoderamento de pacientes com doenças crônicas. Ciênc. saúde coletiva [Internet]. 2012 Nov [cited 2019 June 08];17(11):2923-2930. Available from: http://www.scielo.br/scielo.php?script=sci_arttext\&pid=S141381232012001100009\&lng=en. http://dx.doi.org/10.1590/S1413-81232012001100009.

7. Davies MJ, Heller S, Skinner TC, Campbell MJ, Carey ME, Cradock S. et al. Effectiveness of the diabetes education and self-management for ongoing and newly diagnosed (DESMOND) programme for people with newly diagnosed type 2 diabetes: cluster randomised controlled trial. BMJ. 2008;336(7642):491-5.

8. Funnell MM, Brown TL, Childs BP, Haas LB, Hosey GM, Jensen B, et al. National standards for diabetes selfmanagement education. Diabetes Care. 2010;33(Suppl 1):89-96. 
9. Cyrino AP, Schraiber LB, Teixeira RR. Education for type 2 diabetes mellitus self-care: from compliance to empowerment. Interface. 2009;13(30):93-106.

10. Jarvis J, Skinner TC, Carey ME, Davies MJ. How can structured self-management patient education improve outcomes in people with type 2 diabetes? Diabetes Obes Metab. 2010;12(1):12-9.

11. Potter PA, Perry AG. Cuidado nas famílias. In: Potter PA, Perry AG, organizadores. Fundamentos de Enfermagem. $9^{\mathrm{a}}$ ed. Rio de Janeiro (RJ): Guanabara Kogan; 2018. p.117-29.

12. Costa JA, Balga RSM, Alfenas RCG, Cotta RMM. Promoção da saúde e diabetes: discutindo a adesão e a motivação de indivíduos diabéticos participantes do programa da saúde. Cienc Saúde Coletiva. 2011;16(3):2001-9.

13. Bardin L. Análise de Conteúdo. Lisboa, Portugal: Edições 70, LDA; 2016.

14. Silva JVM, Mantovani MF, Kalinke LP, Ulbrich EM. Avaliação do Programa de Hipertensão Arterial e Diabetes Mellitus na visão dos usuários. Rev Bras Enferm. 2015;68(4):626-32.

15. Novais EE, Conceição AP, Domingos J, Duque V. People with chronic diseases and their knowledge about self-care. Rev HCPA. 2009;29(1):36-44.

16. Zanetti ML, Biagg MV, Santos MA, Péres DS, Teixeira CRS. O cuidado à pessoa diabética e as repercussões na família. Rev Bras Enferm. 2008;61(2):186-92.

17. Lopes AAF, Cuidado e Empoderamento: a construção do sujeito responsável por sua saúde na experiência do diabetes. Saude soc. 2015;24(2):486-500.

18. Macedo MML, Cortez DN, Santos JCRIA, Torres HC. Adesão e empoderamento de usuários com diabetes mellitus para práticas de autocuidado: ensaio clínico randomizado. Rev. esc. enferm. USP [Internet]. 2017 [cited 2020 Mar 08];51:e03278. Available from: http://www.scielo.br/scielo.php?script=sci_arttext\&pid=S00802342017000100467\&lng=en. Epub Dec 18, 2017. https://doi.org/10.1590/s1980-220x2016050303278.

19. Scott JG. Uma categoria útil para a análise histórica. Educ Real. 1995;20(2):71-99.

20. Knauth DR, Couto MT, Figueiredo WS. A visão dos profissionais sobre a presença e as demandas dos homens nos serviços de saúde: perspectivas para a análise da implantação da Política Nacional de Atenção Integral à Saúde do Homem. Cienc Saúde Coletiva. 2012;17(10):2617-26.

\author{
Endereço do primeiro autor: \\ Geysa Maria Nogueira Farias \\ Universidade de Fortaleza \\ Av. Washington Soares, 1321 \\ Bairro: Edson Queiroz \\ CEP: 60811-905 - Fortaleza - CE - Brasil \\ E-mail: geysafarias@unifor.br
}

\title{
Endereço para correspondência:
}

Danielle Teixeira Queiroz

Universidade de Fortaleza

Av. Washington Soares, 1321

Bairro: Edson Queiroz

CEP: 60811-905 - Fortaleza - CE - Brasil

E-mail: dteixeiraqueiroz@yahoo.com.br 